\title{
Comparação do número de corpos de neurônios em diferentes giros do córtex cerebral de cães desnutridos
}

\author{
Comparison of the neuron bodies number in different gyrus of brain cortex of malnourished \\ dogs
}

\author{
Nara Carpinelli CAETANO ${ }^{1}$; Carla Martins de MELO $^{1}$; Denismar Alves NOGUEIRA ${ }^{1}$; Wagner Costa \\ ROSSI JUNIOR ${ }^{1}$; Alessandra ESTEVES ${ }^{1}$
}

\author{
${ }^{1}$ Universidade Federal de Alfenas, Alfenas-MG, Brasil
}

\begin{abstract}
Resumo
Este trabalho teve por objetivo estudar possíveis alterações quantitativas em corpos de neurônios do córtex cerebral de cães, causadas pela desnutrição. Foram utilizados sete encéfalos de cães machos sem raça definida, diagnosticados desnutridos, para a realização deste estudo. Foram definidos diferentes giros do córtex cerebral a serem estudados; estes foram amostrados, processados pelo procedimento histológico de rotina e corados pelo método de violeta cresil modificado, para visualização dos corpos de neurônios. As lâminas foram analisadas à ocular de 20 vezes. Os resultados obtidos revelaram uma diminuição expressiva na quantidade de corpos de neurônios nos cães desnutridos $(10,8)$, quando comparados aos cães normonutridos (16,35), concluindo que possivelmente a desnutrição é um fator de diminuição do número de corpos de neurônios no córtex cerebral de cães desnutridos, quando comparados a normonutridos.
\end{abstract}

Palavras-chave: Desnutrição. Corpos de neurônios. Córtex cerebral. Cães.

\begin{abstract}
The aim of this study was to verify the quantitative alterations of the neurons bodies in the brain cortex of malnourished dogs. Seven brains of mongrel male dogs that were previously diagnosticated as malnourished were collected. The dogs had similar constitutionalist characteristics of cranium (mesaquicefalus). It was chosen different gyrus of the brain cortex to been study; those gyrus were sampled, prepared according to conventional histological technique and stained by modified cresil violet, for becoming evident the neurons bodies. The slides were analyzed with the $20 \mathrm{x}$ ocular. Our results indicate a expressive reduction in the number of neuron bodies in malnourished dogs $(10,8)$, when compared with dogs in normal nutrition conditions $(16,35)$. In conclusion, it's possible that the malnutrition leads to an reduction of neurons bodies in brain cortex of dogs, when compared to those with normal condition of nutrition.
\end{abstract}

Keywords: Malnutrition. Neurons bodies. Brain cortex. Dogs.

\section{Introdução}

A desnutrição proteico-energética é um distúrbio nutricional resultante da carência geral de calorias e/ ou nutrientes necessários para mínima condição de sobrevivência. Atualmente, esta condição acomete milhões de pessoas e se caracteriza como um problema social e individual exacerbante, podendo acarretar sérios déficits no organismo portador.

A desnutrição é causada principalmente pela ingestão insuficiente de alimentos para seu desenvolvimento e funcionamento, mas pode também dar-se por escassez de determinados nutrientes isoladamente, por deficiência no processo de metabolização e/ou utilização de nutrientes, sendo assim, de origem multifatorial e intimamente relacionada à pobreza, baixo nível social e dificuldade de acesso a alimentos.

Como em qualquer sistema fisiológico, o sistema nervoso necessita de nutrientes (adquiridos por uma

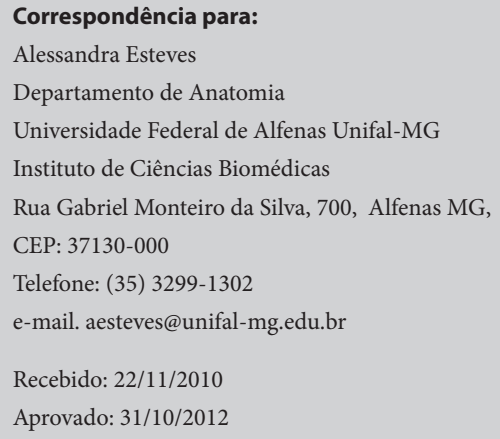


dieta saudável, harmônica e equilibrada) para que haja um bom rendimento de suas funções. $\mathrm{O}$ cérebro utiliza alta taxa de energia, proveniente das proteínas e glicose, para tais funções e manutenção. Esse consumo alto de energia pelo encéfalo reflete o fato de que bilhões de neurônios precisam gerar e manter gradientes eletroquímicos através de suas membranas celulares, utilizados para produzir impulsos neuronais ${ }^{1}$. Foi demonstrado que mudanças morfométricas permanentes e transitórias podem ocorrer no córtex visual de ratos desnutridos no início da vida, mesmo após recuperação do estado nutricional ${ }^{2,3}$.

O estado nutricional é um importante fator para o desenvolvimento e organização funcional do Sistema Nervoso Central (SNC), estando diretamente relacionado à energia e aos nutrientes utilizados para desenvolvimento e manutenção dos vários sistemas metabólicos existentes no organismo ${ }^{4}$. A maturação do SNC e o desenvolvimento de sua capacidade dependem de três fatores: genética do organismo, estimulação ambiental e nutrientes disponíveis ${ }^{5}$.

Alterações neurofisiológicas também são amplamente encontradas e frequentes na desnutrição proteico-energética. Dentre elas, está o prejuízo na plasticidade sináptica, que pode fornecer informações de como a desnutrição afeta o desenvolvimento cerebral, em sua ocorrência pré-natal, aprendizagem e memória ${ }^{6}$.

A ampla literatura, baseada predominantemente em modelos de experimentação, pelas inerentes e óbvias dificuldades éticas na avaliação dos efeitos da desnutrição humana sobre o sistema nervoso central, aponta para a amplitude do espectro das consequências da desnutrição a longo prazo, reduzindo a capacidade de desenvolvimento pleno das capacidades e da qualidade da vida, especialmente quando ocorrem em período de rápido crescimento cerebral.

A realidade dos animais não é diferente da humana e, muitas vezes, é ainda pior. Nosso trabalho buscou estudar diferenças quantitativas dos corpos de neurônios em diferentes giros cerebrais de cães desnutridos, sendo esta patologia comumente presente no cotidiano dos cães.

\section{Material e Método}

O estudo foi realizado nos Laboratórios de Anatomia e Histologia da Universidade Federal de Alfenas (Alfenas - MG). O projeto de pesquisa foi encaminhado à apreciação do Comitê de Ética em Pesquisa e ao Comitê de Ética na Experimentação Animal - CEEA da Universidade Federal de Alfenas - UNIFAL-MG, registro no 224/2009. Após parecer favorável, iniciou-se o experimento.

Foram utilizados sete cães sem raça definida com comprovada desnutrição (os cães foram gentilmente cedidos pelo Centro de Controle de Zoonoses de Alfenas - CCZ/Alfenas), de acordo com a anamnese realizada pelo veterinário responsável, na qual foram avaliados: temperatura, tempo de preenchimento capilar (TPC), frequência respiratória e cardíaca; grau de hidratação; mucosa oral e ocular; avaliação da condição geral do animal além do Índice de Massa Corporal Canino (IMCC) de acordo com Muller, Schossler e Pinheiro7; o IMCC ideal para cães cujo tipo físico é de médio porte (peso médio entre 10 e $25 \mathrm{~kg}$ ) compreende valores entre 11,8 e $15 \mathrm{~kg} . \mathrm{m}^{-2}$. Sendo assim, um animal que possuía o peso $20 \%$ abaixo do peso ideal pode ser considerado desnutrido.

Foram excluídos também da casuística selecionada casos de cães com doenças prévias virais, bacterianas, neoplásicas e/ ou parasitológicas que possivelmente pudessem afetar o número de neurônios dos mesmos.

Os animais foram eutanasiados, dando início à retirada dos encéfalos. A artéria carótida comum de cada animal foi canulada para efetuar-se a perfusão com 4\% de paraformaldeído em solução tampão fosfato, pH 7,4 (Paraformaldehyde - Sigma Chemical Co. USA). A cabeça de cada animal foi isolada, re- 
movida e promoveu-se, então, a retirada dos encéfalos, que foram armazenados em vidros de coleta devidamente identificados, contendo $4 \%$ de paraformaldeído (Paraformaldehyde - Sigma Chemical Co, St. Louis, MO, USA) em solução tampão fosfato $\mathrm{pH} 7,4$. Os encéfalos permaneceram imersos na solução tampão fixadora por três semanas, seguindo o protocolo utilizado por Rabinowicz et $\mathrm{al}^{8}$. Em cada encéfalo foram definidos diferentes giros do córtex cerebral, nos dois hemisférios cerebrais (Figura 1). Foi retirada uma amostra de cada local medindo 2 $\mathrm{X} 0,5$ X $1,0 \mathrm{~cm}$.

Os fragmentos foram processados, seguindo-se da sequência padronizada nos procedimentos histológicos convencionais: desidratação em álcool, diafanização em xilol e inclusão em parafina (Histosec ${ }^{\circledR}$, Merck, Frankfurt, Germany) ${ }^{9}$. Cada região foi emblocada e cortada com espessura de $5 \mu \mathrm{m}$ em micrótomo Leica 2165. De cada região, foram feitos cinco cortes sequenciais que foram corados pelo método de coloração de violeta cresil modificado, para facilitar a visualização dos Corpúsculos de Nissl e, assim, possibilitar marcar fortemente e individualmente cada célula para posterior contagem.

Com base na literatura consultada, optou-se pela escolha do método de contagem "visual" por área, como preconizado para sistema nervoso central por Michon et al. ${ }^{10}$ e Rabinowicz et al. ${ }^{11}$. As lâminas foram examinadas à ocular de vinte vezes, com auxílio de um microscópio óptico Axióscopio Zeiss ${ }^{\circledR}$, acoplado a uma câmera de vídeo e monitor de um computador. Os cortes foram submetidos a um sistema KS-400 versão 2.0 Kontron - Zeiss ${ }^{\circledR}$, analisando-se a quantidade de neurônios expressa em números por área escolhida, através da contagem manual ${ }^{10}$. Para análise quantitativa, foram selecionados cinco cortes sequenciais por região, totalizando $35 \mathrm{em}$ cada hemisfério cerebral e 70 cortes por animal, somando-se ao final 490 cortes, seguindo-se a mensuração manual. Em cada corte foram contados cinco campos distintos, obtendo-se deles uma média; das cinco médias obteve-se uma média final para análise estatística. Cada análise foi realizada por mais de um observador, a fim de evitar possíveis vieses de contagem. Os dados foram analisados com o programa Sisvar 5.1 Build $72^{12}$, onde foram realizadas Análises de Variância e, quando verificado o efeito significativo, utilizou-se o Teste de Tukey para discriminar as diferenças e/ou igualdades entre as médias avaliadas.

Esteves, Prada e Carvalho ${ }^{13}$ realizaram um trabalho com a contagem do número de corpos de neurônios em diferentes áreas do córtex cerebral de cães em estado normal de nutrição, o qual foi utilizado como comparativo para este trabalho.

\section{Resultados}

As análises das lâminas levaram à contagem do número de corpos de neurônios em diferentes giros cerebrais em cães amostrados desnutridos, chegando-se à média final (Gráfico 1).

As médias de corpos de neurônios entre os diferentes giros foram comparadas estatisticamente pela Análise de Variância (Tabela 1), mostrando que as comparações feitas das médias dos corpos de neurônios contados entre os giros estudados foram significativas. $\mathrm{Na}$ análise entre os diferentes hemisférios não foi observado significância, assim como a interação hemisfério $\mathrm{x}$ giro, demonstrando que não há interação entre esses fatores (hemisfério e giro).

O Teste de Tukey veio a seguir (Tabela 2), evidenciando que os giros 7,4 e 1 não diferem significativamente no número de corpos de neurônios; os giros 1, 6, 2 e 5 também mantêm o padrão e não diferem significativamente entre si e, por fim, os giros 5 e 3 não diferem significativamente, sendo que o giro 7 foi o que apresentou o maior número de corpos de neurônios contados $(17,18)$ e o giro 3 foi o que apresentou o menor número $(11,43)$. O número médio de corpos 


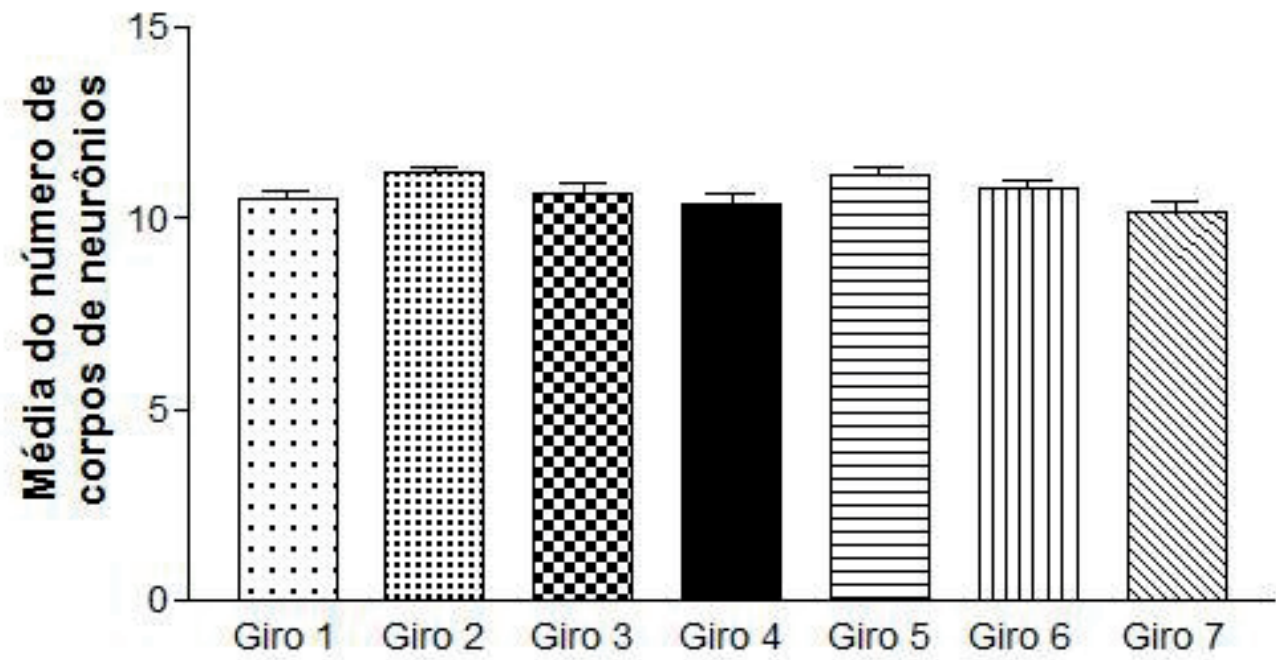

Gráfico 1 - Diferença do número de corpos de neurônios entre os giros cerebrais dos cães desnutridos

Tabela 1 - Resumo da Análise de Variância segundo giro, hemisfério, e interação giro $\mathrm{x}$ hemisfério - Alfenas - 2010

\begin{tabular}{lccccc}
\hline FV & GL & SQ & QM & Fc & Pr $>$ Fc \\
\hline GIRO & 6 & 19.807196 & 3.301199 & 3.741 & 0.0024 \\
HEMISFÉRIO & 1 & 1.609731 & 1.609731 & 1.824 & 0.1805 \\
GIROHEMISFÉRIO & 6 & 3.959984 & 0.659997 & 0.748 & 0.6128 \\
erro & 84 & 74.133600 & 0.882543 & & \\
\hline Total corrigido & 97 & 99.510510 & & \\
\hline CV (\%) & 8.70 & & & \\
\hline Média geral & 10.8026531 & Número de observações: & \\
\hline
\end{tabular}

de neurônios quantificados nos diferentes giros cerebrais foi de 10,8 (Gráfico 2).

\section{Discussão}

Diversos estudos mostrando os efeitos da desnutrição no sistema nervoso central de cobaias vêm sendo desenvolvidos. Nosso estudo teve como animal experimental o cão, visto que estes são vítimas de maus tratos e abandono, assim sendo a desnutrição uma realidade muito comum.
Fiorini et al. ${ }^{14}$ e Sônia Trannin de Mello et al. ${ }^{15}$ verificaram que não houve efeito periférico no que diz respeito à densidade neuronal de neurônios do íleo e do jejuno, respectivamente, de ratos submetidos à desnutrição. Nossos dados diferem dos obtidos por estes estudos, sugerindo uma diminuição no número de corpos de neurônios corticais de cães, sendo este um efeito referente ao sistema nervoso central.

Há estudos que apresentam resultados semelhantes aos obtidos em nosso trabalho, porém, diferindo de modelos experimentais, ou de área a ser analisada. 


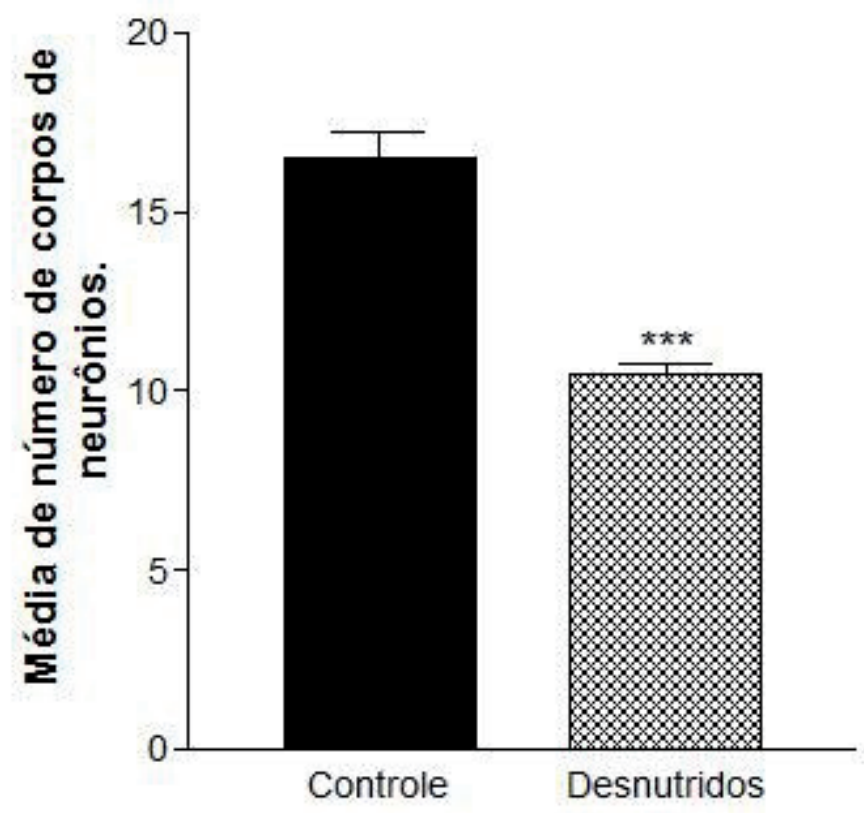

Gráfico 2 - Comparação entre o número de corpos de neurônios entre cães normonutridos ${ }^{13}$ e desnutridos

Tabela 2 - Comparação das médias entre os diversos giros cerebrais - Alfenas - 2010

\begin{tabular}{cccc}
\hline Tratamentos & Médias & Resultados do teste \\
\hline G7 & 10.187143 & a1 & \\
G4 & 10.326429 & a1 & a2 \\
G1 & 10.483571 & a1 & a2 \\
G6 & 10.775714 & a1 & a2 \\
G2 & 11.192143 & a1 & a2 \\
G5 & 11.216429 & a1 & a2 \\
G3 & 11.427143 & & a2 \\
\hline
\end{tabular}

Sant’ana, Milinari e Miranda-Neto ${ }^{16}$ verificaram, além de outros parâmetros, uma diminuição no número de neurônios nitrérgicos e de neurônios $\mathrm{NADH}$ -diaforese do cólon de ratos submetidos à desnutrição proteica de vitamina B. Gomes et al. ${ }^{17}$ estudaram os efeitos da desnutrição proteica no gânglio celíaco de ratos submetidos à desnutrição. Foi observada atrofia do órgão e dos neurônios nele presente, e ainda perda neuronal de $63 \%$ nos animais desnutridos. Lister et al. ${ }^{18}$ observaram redução de $20 \%$ no número de neurônios do subcampo CA1 de ratos submetidos à desnutrição pré-natal. Ainda, observaram redução do volume de CA1 e da camada piramidal do subículo, o que é relacionado com prejuízos na via tri-sináptica, essencial para memória e aprendizagem. Um dos fatores alarmantes em relação à desnutrição é ter algumas atividades cognitivas prejudicadas, no que se refere às funções afetadas no Sistema Nervoso Central. Nossos achados lidam com uma perda nervosa grande, o que também poderia ser ligado à diminuição das capacidades cognitivas normais do indivíduo. Perdas expressivas em áreas de funções superiores teriam maiores efeitos clínicos observáveis. Ainda, perdas no córtex cerebral terão sempre efeitos clínicos, uma vez que ele faz parte de todo processamento de informações pelo encéfalo.

Pernille Tveden-Nyborg et al. ${ }^{19}$ relataram desenvolvimento neuronal debilitado e diminuição da memória espacial em cobaias submetidos à deficiência de Vitamina C no início da vida pós-natal. Almeida et al. ${ }^{20}$ mostraram em seu estudo que a desnutrição mul- 


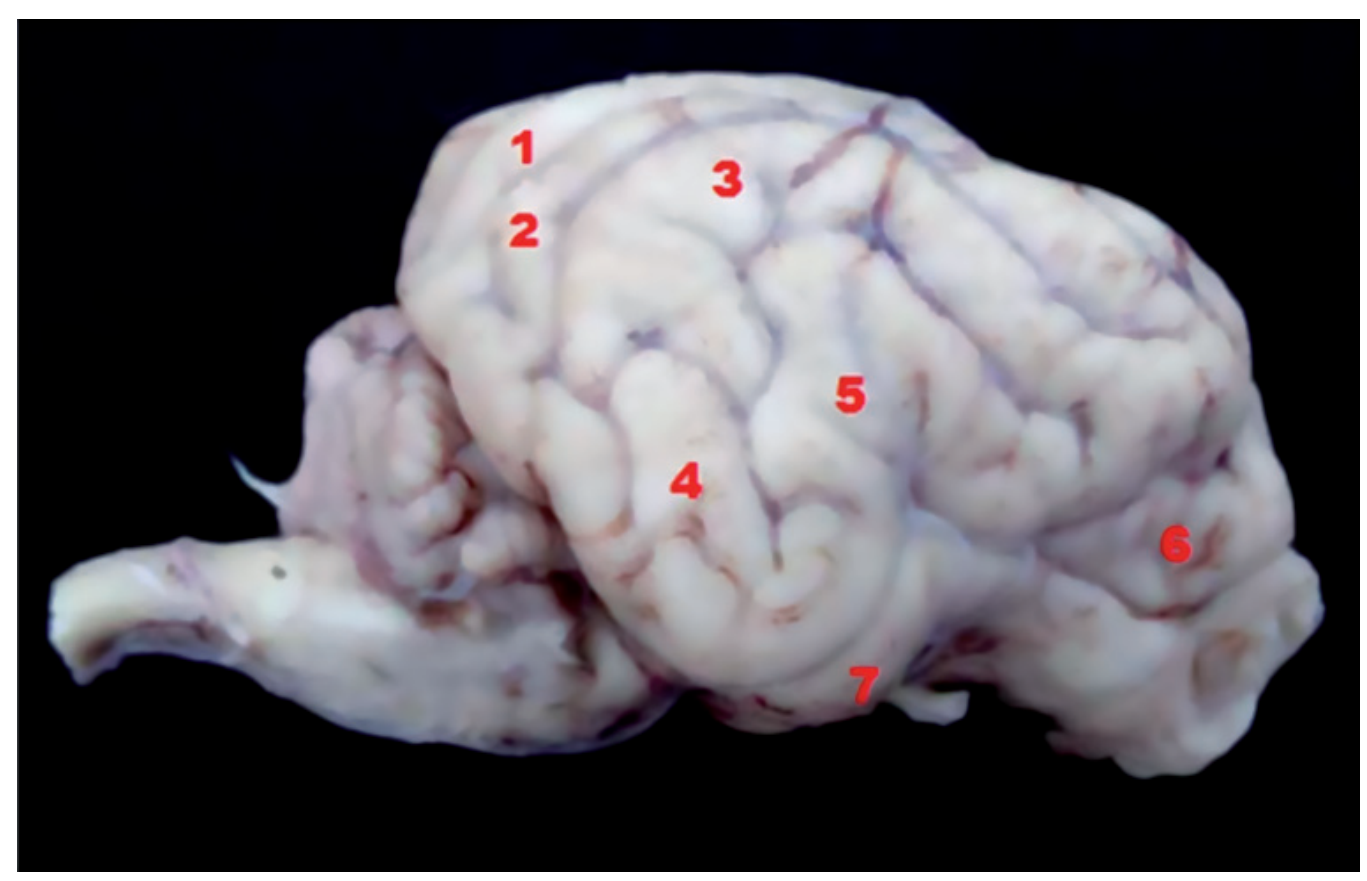

Figura 1 - Fotografia macroscópica da vista lateral do encélafo do cão, identificando-se as áreas corticais definidas para colheita de material (1 - Giro marginal; 2- Giro ectomarginal; 3- Giro Supra-silviano; 4 - Giro ectossilviano; 5 - Giro silviano; 6 - Giro pró-reus; 7 Lobo piriforme)

tideficiente no início da vida de ratos afeta permanentemente a organização e mielinização do nervo óptico, indicando uma transmissão no nervo deficiente, provavelmente, uma disfunção na habilidade visual. Estes achados são acrescidos dos nossos, uma vez que os déficits cognitivos e comportamentais causados pela desnutrição proteico-energética são tamanhos que podem ser relacionados ao desenvolvimento neuronal deficiente, pelo menor número de neurônios e pela transmissão deficiente, causados não necessariamente juntos nem com uma ordem específica, mas que se somam e, então são altamente prejudiciais ao organismo.

$\mathrm{O}$ resultado do número médio de corpos celulares de neurônios $(10,8)$ obtido neste estudo é contrastante com o obtido com cães normonutridos $(16,35)$ por
Esteves, Prada e Carvalho ${ }^{13}$ e evidencia uma redução altamente expressiva entre as médias analisadas.

\section{Conclusão}

Os presentes resultados evidenciam que há uma diminuição expressiva no número de corpos de neurônios quantificados em áreas do córtex cerebral de cães desnutridos, quando comparados a cães em condições normais de nutrição.

Ainda, a análise crítica dos dados ressalta que há diferenças estatísticas significativas do número de corpos de neurônios quantificados, nos diversos giros em estudo. Os dados evidenciam como sendo o giro 7 (lobo piriforme) o portador do maior número de corpos de neurônios por área e o giro 3 (giro supra-silviano), o menor. 


\section{Referências}

1. GIBNEY, M. J.; MACDONALD, I. A.; ROCHE, H. M. Nutrição \& metabolismo. Rio de Janeiro: Guanabara Koogan, 2006. 351 p.

2. BORBA, J. M. S.; ARAÚJO, M. S.; PICANCO-DINIZ, C. W.; MANHÃES-DE-CASTRO, R.; GUEDES, R. C. Permanent and transitory morphometric changes of NADPdiaphorasecontaining neurons in the rat visual cortex after early malnutrition. Brain Research Bulletin, v. 53, n. 2, p. 193-201, 2000.

3. MAIA, L. M. S. S.; FRAZÃO, M. F.; SOUZA, T. K.; SILVA, M. B.; ROCHA-DE-MELO, A. P.; PICANÇO-DINIZ, C. W.; AMÂNCIO-DOS-SANTOS, A.; GUEDES, R. C. L- arginine treatment early in life influences NADPH-diaphorase neurons in visual cortex of normal and early-malnourished adult rats. Brain Research, v. 1072, n. 1, p. 19-25, 2006.

4. MORGANE, P. J.; AUSTIN-LAFRANCE, R. J.; BRONZINO, J. D.; TONKISS, J.; GALLER, J. R. Malnutrition and the developmeing central nervous system. In: ISSACSON, R. L.; JENSEN, K. F. (Ed.). The vulnerable brain and environmental risks: malnutrition and hazard assessment. New York: Plenum Press, 1992. v. 1, p. 3-44.

5. GALLER, J. R.; SHUMSKY, J. S.; MORGANE, P. J. Malnutrition and brain development. In: Nutrition Pediatrics. 2. ed. New York: Plenum Press, 1995. cap. 14, p. 1-55.

6.MORGANE, P. J.; AUSTIN-LAFRANCE, R.; BRONZINO, J.; TONKISS, J.; DÍAZ-CINTRA, S.; CINTRA, L.; KEMPER, T.; GALLER, J. R. Prenatal malnutrition and development of the brain. Neuroscience Bioberavuiral Reviews, v. 17, n. 1, p. 91-128, 1993.

7. MUller, D. C. M.; SCHOSSLER, J. E.; PINHEIRO, M. Adaptação do índice de massa corporal humano para cães. Ciência Rural, v. 38, n. 4, p. 1038-1043, 2008.

8. RABINOWICZ, T.; DEAN, D. E.; PETETOT, J. M. C.; MYERS, G. M. C. Gender differences in the human cerebral cortex: more neurons in males; more processes in females. Journal of Child Neurology, v. 14, n. 2, p. 98-107, 1999.

9. BEHMER, O. A.; TOLOSA, E.; FREITAS, A. G. N. Manual de técnicas para histologia normal e patológica. São Paulo: EDART, 1976. $241 \mathrm{p}$.

10.MICHON, J. J.; LI, Z. L.; SHIOURA, N.; ANDERSON, R. J.; TSO, M. O. A comparative study of methods of photoreceptor morphometry. Investigative Ophthalmology e Visual Science, v. 32, n. 2, p. 280-284, 1991.

11.RABINOWICZ, T.; PETETOT, J. M.; GARTSIDE, P. S.;
SHEYN, D.; SHEYN T, C. M. Structure of the cerebral cortex in men and women. Journal of Neuropathology and Experimental Neurology, v. 61, n. 1, p. 46-67, 2002.

12.FERREIRA, D. F. Sisvar: um programa para análises e ensino de estatística. Revista Symposium (Lavras), v. 6, p. 36-41, 2008.

13.ESTEVES, A.; PRADA, I. L. S.; CARVALHO, A. F. Comparação do número de corpos de neurônios de áreas do córtex cerebral de cães. Brazilian Journal of Veterinary Research and Animal Science, v. 41, n. 5, p. 332-338, 2004.

14.FIORINI, S.; MOLINARI, S. L.; NATALI, M. R. M.; MIRANDA NETO, M. H. de. Quantitative morphological analysis of the myenteric neurons of the ileum in rats under experimental desnutrition. Acta Scientiarum, v. 21, n. 2, p. 409-413, 1999.

15. MELLO, S. T.; MELLO, S. T. de; LIBERTI, E. A.; SANT'ANA, D. M. G.; MOLINARI, S. L.; MIRANDA NETO, M. H. de. Estudo morfoquantitativo do plexo mioentérico do duodeno de ratos submetidos a carência de proteínas e vitaminas do complexo B. Acta Scientiarum Biological Sciences, v. 26, n. 2, p. 251-256, 2004.

16.SANT'ANA, D. M. G.; MOLINARI, S. L.; MIRANDA-NETO, M. H. Effects of protein and vitamin B deficiency on blood parameters and myenteric neurons of the colon of rats. Arquivos Neuro-Psiquiatria, v. 59, n. 3A, p. 493-498, 2001.

17.GOMES, S. P.; NYENGAARD, J. R.; MISAWA, R.; GIROTTI, P. A.; CASTELUCCI, P.; BLAZQUEZ, F. H.; DE MELO, M. P.; RIBEIRO, A. A. Atrophy and neuron loss: effects of a proteindeficient diet on sympathetic neurons. Journal Neuroscience Research, v. 87, n. 16, p. 3598-3575, 2009.

18.LISTER, J. P.; BLATT, G. J.; DEBASSIO, W. A.; KEMPER, T. L.; TONKISS, J.; GALLER, J. R.; ROSENE, D. L. Effect of prenatal protein malnutrition on numbers of neurons in the principal cell layers of the adult rat hippocampal formation. Hippocampus, v. 15, n. 13, p. 393-403, 2005.

19.TVEDEN-NYBOR, P.; RAIDA, Z.; VILLUMSEN, C. K.; LARSEN, J. O.; LYKKESFEKDT, J. Vitamin C deficiency in early postnatal life impairs spatial memory and reduces the number of hippocampal neurons in guinea pigs. American Journal Clinical Nutrition, v. 90, n. 3, p. 540-546, 2009.

20. AMEIDA, M. F; SILVEIRA, A. C.; GUEDES, R. C.; HOKOÇ, J. N.; MARTINEZ, A. M. Quantitative ultrastructural evidence of myelin malformation in optic nerves of rats submitted to a multideficient diet. Nutritional Neuroscience, v. 8, n. 2, p. 91-99, 2005. 